Abstract

\title{
Thermal Activity Surveillance System: Measuring Mountain Bike Trail Use ${ }^{\dagger}$
}

\author{
Mark Philip Philipsen *, Louise Abela, Rikke Gade and Thomas Moeslund \\ Media Technology, Aalborg University, Rendsburggade 14, 9000 Aalborg, Denmark; \\ louise.abela.la@gmail.com (L.A.); rg@create.aau.dk (R.G.); tbm@create.aau.dk (T.M.) \\ * Correspondence: mpph@create.aau.dk \\ + Presented at the 5th International Symposium on Sensor Science (I3S 2017), Barcelona, Spain, \\ 27-29 September 2017.
}

Published: 13 February 2018

We present a small system for counting and classifying bikers and pedestrians on nature trails. The system consists of a low-cost capture system based on the Raspberry Pi 2 and an embedded thermal camera. Besides the benefit of enabling both day- and night-time surveillance, thermal imaging also helps address the privacy concerns that usually plague surveillance systems. The camera is very low resolution, but it is able to provide sufficient information for a detector to locate and discriminate between bikers and pedestrians. The detector uses a typical sliding window-based approach and performs classification based on HoG features. Detections are collected in tracks from which a final decision is made on whether a biker or pedestrian has passed through the camera's view. The system is trained and evaluated on a challenging new dataset with more than $25 \mathrm{~h}$ of thermal imagery. Data was captured from varying view points and from multiple geographical locations. The purpose is to show the feasibility of using a collection of classic computer vision methods and low-cost components for a real-time thermal surveillance system that is capable of classifying the different actors that make use of nature trails.

(C) 2018 by the authors. Licensee MDPI, Basel, Switzerland. This article is an open access article distributed under the terms and conditions of the Creative Commons Attribution (CC BY) license (http://creativecommons.org/licenses/by/4.0/). 